\title{
Design and Simulation of Radial Flow Turbine Impeller and Investigation Thermodynamic Properties of Flow in LE and TE
}

\author{
Kiumars Khani Aminjan ${ }^{1}$, Milad Heidari ${ }^{2}$, Pooyan Rahmanivahid ${ }^{2}$, \\ Houman Alipour ${ }^{3}$, Morteza Khashehchi ${ }^{2}$ \\ ${ }^{1}$ Faculty of Aerospace, Malek Ashtar University of Technology, Tehran, Iran \\ ${ }^{2}$ Mechanical Engineering and Vehicle Technology Department, Global College of Engineering and Technology \\ (GCET), P.O. Box 2546 CPO Ruwi 112, Muscat, Sultanate of Oman \\ ${ }^{3}$ Caspian Faculty of Engineering,college of Engineering, university of Tehran, P.O. Box 43841-119, \\ Tehran, Iran
}

\begin{abstract}
Centrifugal (radial flow) turbines are widely used in various industries, including power generation industries, so the study on them is of particular importance. The aim of this study was to investigate the thermodynamic properties of fluid flow in Trailing Edge (TE) and (LE) Leading Edge. For this purpose, first, the rotor (impeller) of the radial flow turbine was designed based on some design data such as flow rate, number of blades, rotational speed, diameter and length of the impeller, and then the designed rotor was simulated in $3 \mathrm{D}$. The simulation done in the pressure based method and the turbulence model is SST and the rotational speed was $140,000(\mathrm{RPM})$. The results showed that the pressure, temperature and enthalpy in TE are less than LE and the areas close to the hub have the highest pressure. Another phenomenon observed is that in the section $L E$ we see the separation of the flow from the blade surface, which then approaches the blade surface again and follows a relatively regular path,
\end{abstract}

DOI: 10.18421/TEM102-62

https://doi.org/10.18421/TEM102-62

Corresponding author: Milad Heidari,

Mechanical Engineering Department, Global College of

Engineering and Technology (GCET), P.O. Box 2546 CPO

Ruwi 112, Muscat, Sultanate of Oman.

Email: milad@gcet.edu.om

Received: 26 January 2021.

Revised: 27 April 2021.

Accepted: 05 May 2021.

Published: 27 May 2021.

(cc) BY-NC-ND (C) 2021 Milad Heidari et al; published by UIKTEN. This work is licensed under the Creative Commons Attribution-NonCommercial-NoDerivs 4.0 License.

The article is published with Open Access at www.temjournal.com so the entropy in TE is greater than LE. At the end, the results of numerical solution were compared with valid data and the error rate and its reasons were discussed.

Keywords - Radial Flow Turbine, Impeller, Trailing Edge, Leading Edge.

\section{Introduction}

Computational fluid dynamics play a greater role in the design of turbomachines than in other engineering tools. For many years, designing an advanced turbine or compressor without using computational fluid dynamics has been unimaginable. In the last two decades, turbomachining companies have used computational fluid dynamics as one of the main methods to evaluate the performance of new designs [1]. In recent years, the design and performance analysis of turbomachines has made significant progress due to the increase in power and accuracy of numerical calculations [2]. Many researchers, such as Paßrucker et al. [3], Cravero [4], oslo Sloteman et al. [5], and Goto et al. [6] proposed integrated methods for designing and analyzing the performance of turbomachines. Many of these methods combine a one-dimensional performance analysis with a quasithree-dimensional method. They numerically simulated their final design using computational fluid dynamics.

Feng et al. [7] designed a small $100 \mathrm{~kW}$ radial turbine rotor for aerodynamic design and numerical simulation. They first performed a thermodynamic design to obtain some important parameters, then designed the traditional cylinders of the turbine rotor using a parabolic geometric design method, and finally evaluated the aerodynamic performance and flow characteristics using Newmka commercial software. They studied the effect of velocity ratio and 
output current coefficient on aerodynamic performance and concluded that when the mass flow rate is high, a high velocity ratio should be selected to reduce the rotor height at the output. This can also reduce the stress on the rotor. They also concluded that for this turbine, the best angle of incidence of the current entering the turbine is -32 degrees relative to the radial direction. Hajilouy and Baines [8] experimentally investigated the performance characteristics of a radial flow turbine and observed that the maximum efficiency decreases with increasing speed. Experimental results of Winterbone et al. [9] for single-inlet turbine showed that there is a sharp drop near the tab in the turbine chamber. So that the low pressure area at an angle of less than 360 degrees, high pressure at an angle of zero degrees and again a pressure drop to an angle of 30 degrees. Tabakof and Sheoram [10] measured the velocity and flow angle in the single-inlet turbine chamber. The results showed that the velocity in the spiral path is continuous and accelerating.

In terms of design, it should be said that in general, the design of radial flow turbine impeller is done in two ways, direct and reverse. In the direct method, the designer first obtains the blade geometry input using boundary conditions such as pressure and stagnation temperature, then enters it into the flow analysis program and changes the blade geometry until it reaches the desired performance. One of the advantages of this method is direct control over the geometric constraints of the problem. In the reverse design method, the designer starts from an initial blade geometry and after analyzing the flow, makes the relevant corrections, and as a result, a new geometry is obtained, and this process is repeated until the desired result is achieved. In the reverse design method, many assumptions are needed, which reduces the accuracy of the solution in this method. Also, to reduce the number of repetitions, it is necessary to use an initial shape that is close to the desired design.

One of the first people to design radial flow turbine wheels was Rohlik [11] in 1968 and Benson [12] in 1977. In 1990, Whitfield [13] studied the dimensionless design of a radial flow turbine. In the method Whitfield proposed, the goal is to minimize the Mach number at the inlet and outlet of the turbine wheel to reduce turbine wheel losses. Minimum losses mean that the flow rate does not exceed the required value. With increasing the speed of the inlet flow to the turbine wheel, the Mach number increases and as a result, the losses also increase. In 1990, Zangeneh [14] used the reverse method to design a three-dimensional impeller. In this method, Zangeneh obtained the tangential three-dimensional shape of the blade by determining the distribution of the tangential component of the average velocity along the blade by flow analysis software and also solving the three-dimensional equations of compressible ultrasonic flow. Due to that, the losses in the initial edge of the blade and the output losses in the end edge of the blade are minimized. Another goal of this distribution was to minimize the amount of rotation in the base profile and achieve a smooth pressure distribution in the Tuk profile. Comparison of the final blade results with the initial blade showed a $5.5 \%$ increase in total return to static. Other researchers have worked on the design of radial flow turbine wheels, including Bains [15], Ebaid [16], and Chiong [17].

The aim of this study was to investigate the thermodynamic properties of fluid flow in Trailing Edge (TE) and (LE) Leading Edge. For this purpose, first the radial flow turbine impeller is designed based on some design data such as flow rate, number of blades, number of revolutions, diameter and length of the impeller (in the present study, the direct design method has been used) and then the designed impeller. Is simulated in $3 \mathrm{D}$ and the results are discussed.

\section{Design and Modeling}

In the preliminary design, which is also called the average line design; it is assumed that all the flow properties in the average radius are equal to the appropriate average of the properties in the flow section. In the preliminary design method, the main dimensions of the turbine impeller are obtained, which include the inlet radius and the outlet radius at the base and tip, the blade width at the inlet and the blade length. The designer needs a series of design parameters to achieve the geometric dimensions of the blade. Basic design parameters include inlet stagnation temperature and pressure, mass flow, total to static pressure ratio, specific velocity, total to static efficiency and specific velocity. In addition to the above, the designer needs a series of geometric constraints such as the absence of the radius of entry into the radius of the tip at the exit, the ratio of the base radius to the tip at the exit and the angle of the blade at the entrance and exit. The fewer designer choices and design code inputs, the more flexible the design. In the present work, an attempt has been made to use the least input data for preliminary design. The algorithm used for the design is shown in Figure 1 below. The algorithm in Figure 1 was repeated until the design requirements were met. The data in Table 1 were used for design. Threedimensional geometry was performed based on the results obtained from the design method using the Blade Gen module of Ansys software. Figure 2 shows the geometry obtained from the design. 


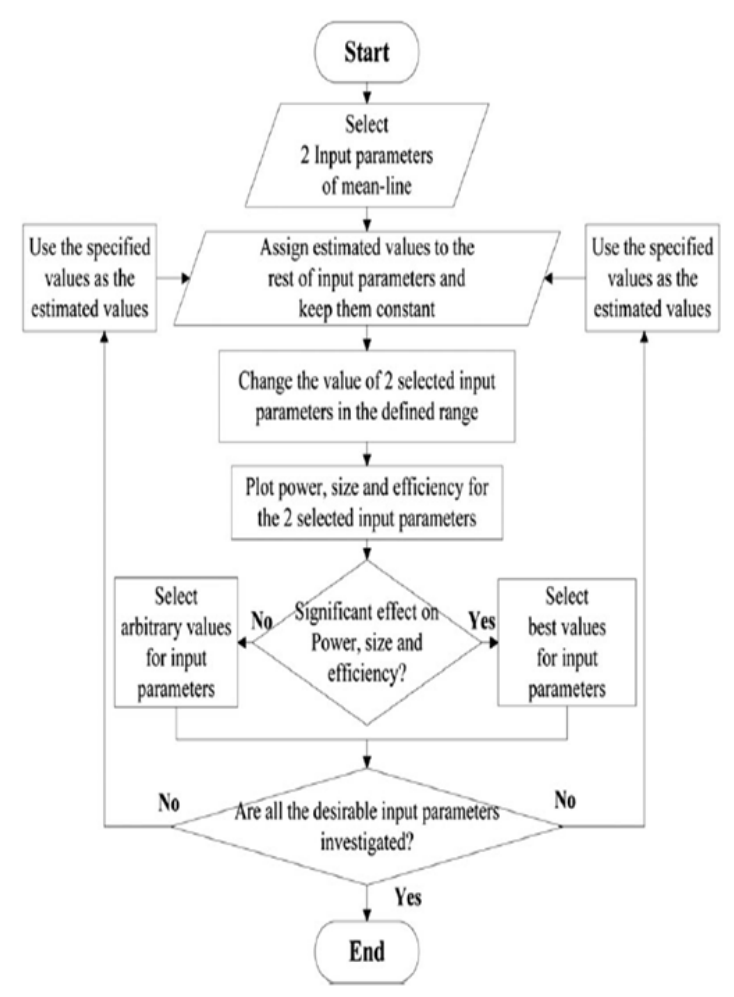

Figure 1. Algorithm for a parametric study of the meanline approach[18].

Table 1. Basic data for design[19]

\begin{tabular}{lc}
\hline \multicolumn{1}{c}{ Parameter } & Quantity \\
\hline Number of blades & 10 \\
$l_{\text {impeller }}$ & $17(\mathrm{~mm})$ \\
$\mathrm{d}_{\text {impeller }}$ & $50(\mathrm{~mm})$ \\
Design mass flow & $69(\mathrm{gr} / \mathrm{s})$ \\
Rotational speed & $140000(\mathrm{rpm})$ \\
Expansion ratio & $1.67-1.82$ \\
Total inlet temperature & $1023.15(\mathrm{~K})$ \\
Absolute inlet flow angle & $73(\mathrm{deg})$ \\
Isentropic Efficiency & 0.75 \\
\hline
\end{tabular}

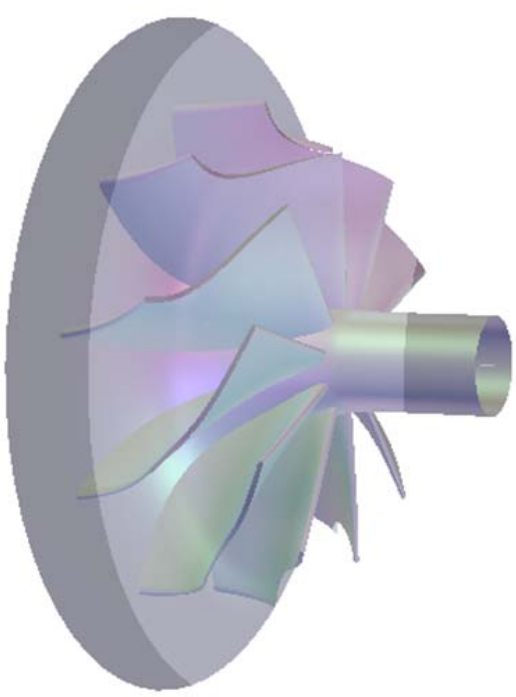

Figure 2. Designed and modeled impeller geometry

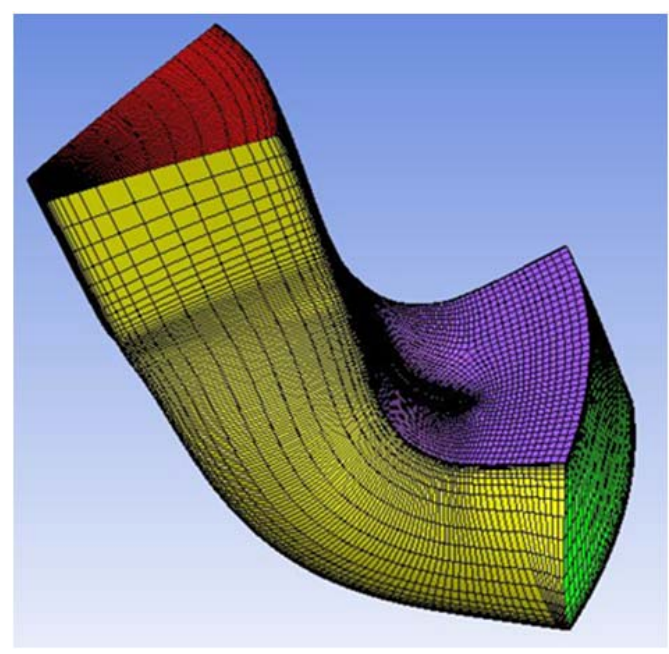

Figure 3. Meshing configuration at an impeller

\section{Meshing}

The next step in producing geometry is to meshing it [20], [21], [23]. The mesh generated for the calculations was performed by the Turbo Grid module of the Ansys software [24], [25] (Figure 3). This software is only developed for the production of meshs for turbomachines, and it is fully organized. The advantage of an organized network is the speed of convergence and high accuracy in the answers. This software has the ability to fine-tune the network in areas where there are strong gradients. There are strong gradients in the areas around the blades and near the walls, so the grid should be smaller in these areas than elsewhere. The independence of numerical solution results was calculated from the number of computational cells for 4 networks with the number of cells 50,000, 100,000, 200,000 and 400,000 and according to the results, 200,000 cells with maximum edge length ratio equal to 346.147 were used for numerical solution.

\section{Governing Equations and Numerical Solution Methods}

Calculating the flow field parameters in turbomachines using computational fluid dynamics is complex, because the flow inside turbomachines is due to the flow separation phenomena. Secondary and reciprocating currents, as well as the compressibility and turbulence of the current, are very complex [26]. The three-dimensional flow inside the turbine is analyzed using CFX software. In this software, the compressible flow equations are solved based on the base pressure method. Equation discretization is performed based on the High Resolution method. Meanwhile, the energy equation is solved independently of the mass and momentum equations. Reynolds stress terms are solved in the momentum transfer equations using the SST turbulence model because this turbulence model is more suitable for turbomachines [22]. In the 
simulations, the fluid type was Air Ideal Gass and Rotational speed $=140000($ RPM). For the boundary conditions in this simulation the values of total temperature and pressure are entered at the inlet. The outlet boundary condition is also determined by static pressure. The boundary condition of the walls is assumed to be adiabatic and the non-slip condition for velocity on the surfaces.

\section{Results and Discussion}

The results of the simulations are shown in Figures 4-9 and Table 2. The transfer of fluid energy to the impeller causes the impeller to rotate. In this process, the fluid energy level decreases. As the simulation results show, the velocity, temperature and pressure of the fluid at the output are less than the input. An important point to note is that energy transfer occurs through a change in the enthalpy of the working fluid. Finally, in fluid mechanics problems, this energy is known as shaft work. It is received from the working fluid. Figure 4 shows the flow lines. As it is clear, the motion of the fluid is a spiral motion which is accompanied by a decrease in velocity. Figure 5 shows the pressure contour in the Trailing Edge section. The results show that the lowest pressure belongs to the central part and the highest pressure belongs to the connection part of the impeller hub. In other parts, the pressure distribution is uniform.

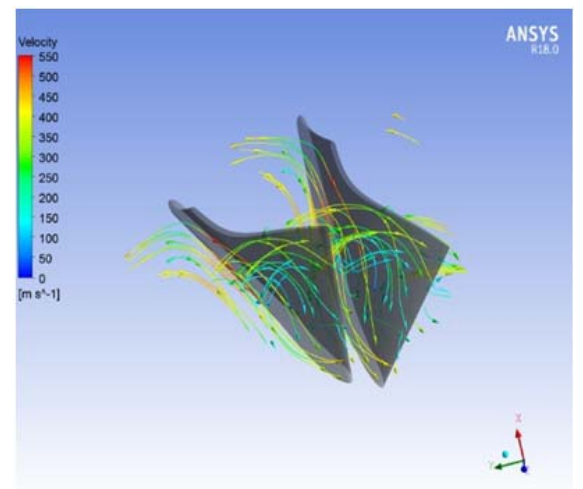

Figure 4. Velocity Streamlines at Blade TE

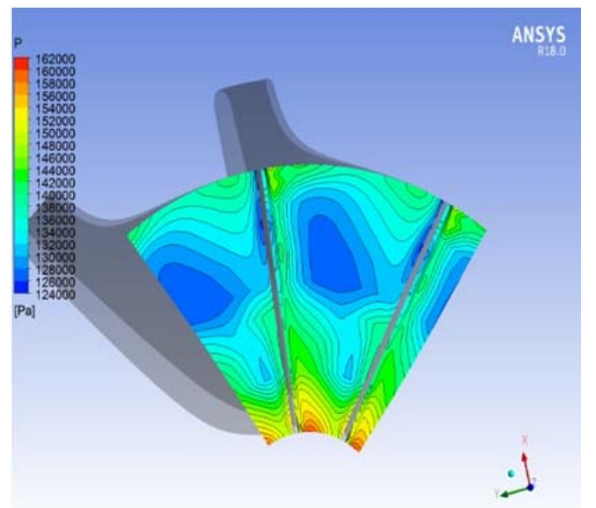

Figure 5. Contour of P at Blade TE
Figure 7 and Figure 6 show the Mach speed velocity contour. These contours show that in the convex part (suction part) the flow has the highest speed and in the concave part (pressure part) the flow has the lowest speed. Another phenomenon that is observed is that in the Leading Edge section, we see the separation of the current from the blade surface, which then approaches the blade surface again and follows an almost regular path. Figure 8 shows the entropy changes. The results show that the highest entropy is related to the Leading Edge where the current separation occurs. Also, the entropy at the output has increased significantly.

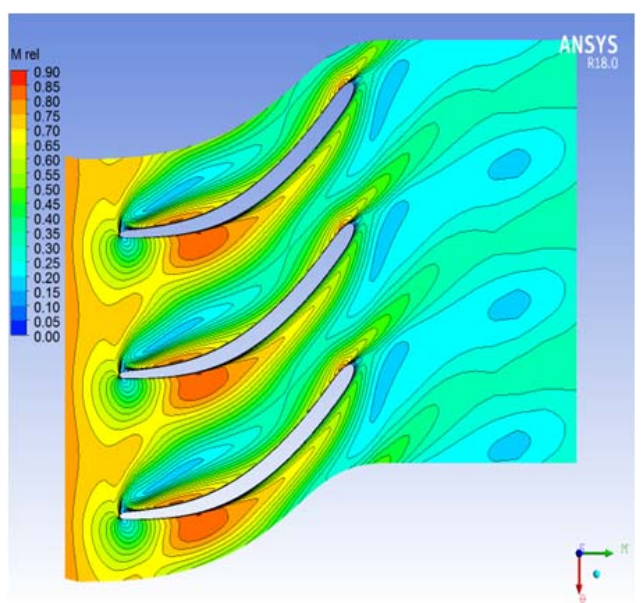

Figure 6. contours of $M$ rel at 50\% span

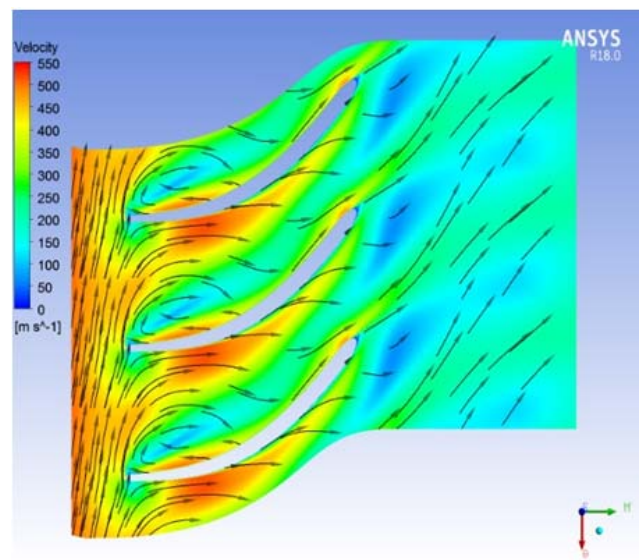

Figure 7. velocity vectors at $50 \%$ span

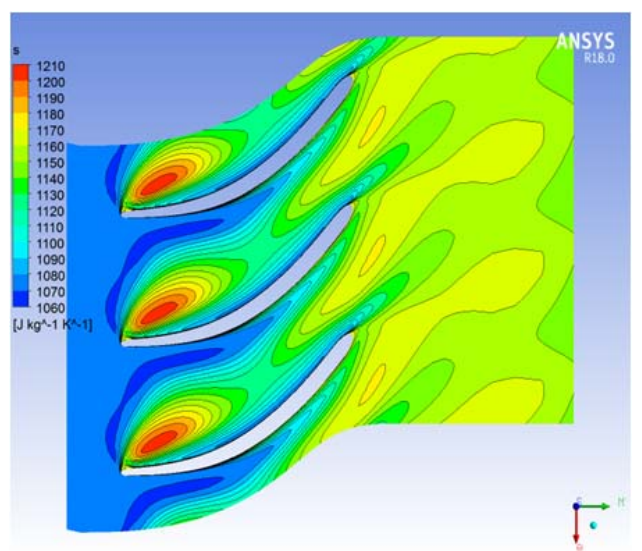

Figure 8. contours of s at $50 \%$ span 


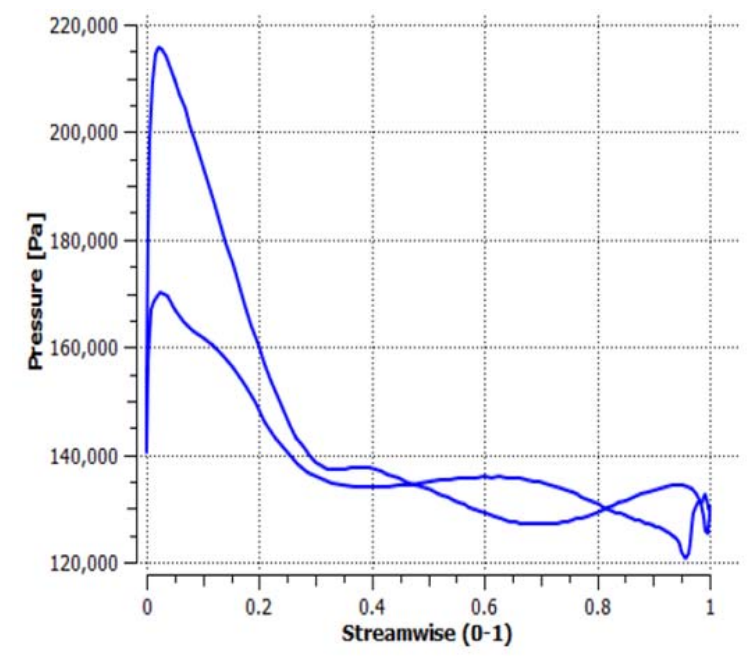

Figure 9. Blade loading chart

Figure 9 shows the pressure distribution on the blade surface. The results of this diagram can be interpreted with the results in Figure 7, i.e. in both the pressure section and the suction section; the pressure distribution is completely opposite to the velocity distribution. The parts that had the highest speed had the least pressure and vice versa.

Table 2. Summary of numerical solution results

\begin{tabular}{lcccc}
\hline \multicolumn{1}{c}{ Quantity } & Inlet & Outlet & LE & TE \\
\hline Density $\left(\mathrm{kg} / \mathrm{m}^{3}\right)$ & 0.6057 & 0.4768 & 0.5933 & 0.4637 \\
$\mathrm{P}(\mathrm{Pa})$ & 178446 & 141369 & 176562 & 135231 \\
$\mathrm{~T}(\mathrm{~K})$ & 1020.65 & 1014.26 & 1016.34 & 987.935 \\
$\mathrm{H}(\mathrm{J} / \mathrm{kg})$ & 725675 & 719261 & 721354 & 692820 \\
$\mathrm{~S}(\mathrm{~J} / \mathrm{kg} . \mathrm{K})$ & 1073.58 & 1128.71 & 1076.81 & 1114.14 \\
Mach(rel) & 0.7886 & 0.3578 & 0.5453 & 0.4239 \\
\hline
\end{tabular}

\section{Validation}

Solutions obtained from numerical methods are not always reliable and the results have to be compared with valid data to prove the accuracy of the solution. Comparing the results of mass flow and expansion ratio obtained in this study with reference [19] in Table 3 shows that the results of this study have an average error of $20.5 \%$. The main cause of this error is related to two factors:
1. The physics governing the flow in turbomachines has many complexities. Although numerical solving methods have advanced a lot in recent years, they are not able to simulate all the details exactly according to the real situation.

2. Some of the data presented in the reference [19] are not explicitly stated and are expressed as a range, so selecting different data from this range will have different results. For example, the value of inlet total pressure is $1.76-1.82$ (bar).

Table 3. Comparison of numerical solution results with reference data

\begin{tabular}{|c|c|c|c|}
\hline Parameter & {$[19]$} & CFD & Error \\
\hline Mass flow rate & $69(\mathrm{gr} / \mathrm{s})$ & $76.8(\mathrm{gr} / \mathrm{s})$ & $11.3 \%$ \\
Expansion ratio & $1.67-1.82$ & 1.2256 & $29.76 \%$ \\
Average error & - & - & $20.5 \%$ \\
\hline
\end{tabular}

\section{Conclusion}

The aim of this study was to investigate the thermodynamic properties of the flow in the Trailing Edge (TE) and Leading Edge (LE) in impeller of a radial flow turbine. First, based on the design requirements, the turbine impeller was designed and modeled by direct method and then the fluid flow simulated by the numerical solution method in the impeller. In summary, the results showed that:

- Pressure, temperature and enthalpy in TE are less than LE.

- In the LE section, we see the separation of the current from the blade surface, which then approaches the blade surface again and follows a relatively regular path, so the entropy in TE is higher than LE.

- The lowest pressure belongs to the central part and the highest pressure belongs to the connection of the impeller to the hub.

\section{Symbols}

P: Pressure $(\mathrm{Pa})$

$\mathrm{T}$ :Temperature $(\mathrm{K})$

$\mathrm{H}:$ Enthalpy $(\mathrm{J} / \mathrm{kg})$

$\mathrm{S}:$ Entropy $(\mathrm{J} / \mathrm{kg} . \mathrm{K})$

TE: Trailing Edge

LE: Leading Edge

M: Mach 


\section{References}

[1]. Denton, J. D., \& Dawes, W. N. (1998). Computational fluid dynamics for turbomachinery design. Proceedings of the Institution of Mechanical Engineers, Part C: Journal of Mechanical Engineering Science, 213(2), 107-124.

[2]. Asuaje, M., Bakir, F., Kouidri, S., Kenyery, F., \& Rey, R. (2005). Numerical modelization of the flow in centrifugal pump: volute influence in velocity and pressure fields. International journal of rotating machinery, 2005(3), 244-255.

[3]. Passrucker, H., \& Van den Braembussche, R. A. (2000). Inverse design of centrifugal impellers by simultaneous modification of blade shape and meridional contour. In ASME Turbo Expo 2000: Power for Land, Sea, and Air. American Society of Mechanical Engineers Digital Collection.

[4]. Cravero, C. (2002, January). A design methodology for radial turbomachinery: Application to Turbines and Compressors. In Fluids Engineering Division Summer Meeting (Vol. 36150, pp. 323-330).

[5]. Sloteman, D., Saad, A., \& Cooper, P. (2001). Designing custom pump hydraulics using traditional methods. Proceedings of ASME FEDSM2001, FEDSM, 18067.

[6]. Goto, A., Nohmi, M., Sakurai, T., \& Sogawa, Y. (2002). Hydrodynamic design system for pumps based on 3-D CAD, CFD, and inverse design method. J. Fluids Eng., 124(2), 329-335.

[7]. Feng, Z., Deng, Q., \& Li, J. (2005, January). Aerothermodynamic design and numerical simulation of radial inflow turbine impeller for a $100 \mathrm{~kW}$ microturbine. In Turbo Expo: Power for Land, Sea, and Air (Vol. 46997, pp. 873-880).

[8]. Hajilouy-Benisi, A., \& Baines, N. C. (1992). Small high speed radial inflow turbine. In Internagional Conference on Engineering Applications of Mechanics.

[9]. Winterbone, D. E., Nikpour, B., \& Alexander, G. I. (1990, May). Measurement of the performance of a radial inflow turbine in conditional steady and unsteady flow. In Proceedings of the 4th International Conference on Turbocharging and Turbochargers (pp. 22-24).

[10]. Tabakoff, W. (1980). Flow Measurements in a Turbine Scroll. ASME Journal of Fluids Engineering, 1980, 291-296.

[11]. Rohlik, H. E. (1968). Analytical determination of radial inflow turbine design geometry for maximum efficiency. National Aeronautics and Space Administration.

[12]. Benson, R. S. (1977). Computer aided design of radial gas turbines: A method for determining the overall rotor dimensions. Computers \& Fluids, 5(4), 219-240.
[13]. Whitfield, A. (1990). The preliminary design of radial inflow turbines. Journal of turbomachinery, 112(1), 50-57.

[14]. Zangeneh, M. (1990, June). Three dimensional design of a high speed radial-inflow turbine by a novel design method. In Turbo Expo: Power for Land, Sea, and Air (Vol. 79047, p. V001T01A082). American Society of Mechanical Engineers.

[15]. Moustapha, H., Zelesky, M. F., Baines, N. C., \& Japikse, D. (2003). Axial and radial turbines (Vol. 2). White River Junction, VT: Concepts NREC.

[16]. Ebaid, M. S. Y., Bhinde, F. S., \& Khadiri, G. H. (2002). A unified approach for designing a radialinfiow gas turbine, ASME Paper.

[17]. Chiong, M. S., Rajoo, S., Martinez-Botas, R. F., \& Costall, A. W. (2012). Engine turbocharger performance prediction: One-dimensional modeling of a twin entry turbine. Energy Conversion and Management, 57, 68-78.

[18]. Rahbar, K., Mahmoud, S., \& Al-Dadah, R. K. (2016). Mean-line modeling and CFD analysis of a miniature radial turbine for distributed power generation systems. International Journal of LowCarbon Technologies, 11(2), 157-168.

[19]. Mueller, L., Alsalihi, Z., \& Verstraete, T. (2013). Multidisciplinary optimization of a turbocharger radial turbine. Journal of Turbomachinery, 135(2).

[20]. Jamali, M., Rostamijavanani, A., Nouri, N. M., \& Navidbakhsh, M. (2020). An experimental study of cavity and Worthington jet formations caused by a falling sphere into an oil film on water. Applied Ocean Research, 102, 102319.

[21]. Rostamijavanani, A., Ebrahimi, M. R., \& Jahedi, S. (2021). Thermal post-buckling analysis of laminated composite plates embedded with shape memory alloy fibers using semi-analytical finite strip method. Journal of Failure Analysis and Prevention, 21(1), 290-301.

[22]. Menter, F. R., Kuntz, M., \& Langtry, R. (2003). Ten years of industrial experience with the SST turbulence model. Turbulence, heat and mass transfer, 4(1), 625632.

[23]. Rostamijavanani, A., Ebrahimi, M. R., \& Jahedi, S. (2021). Free Vibration Analysis of Composite Structures Using Semi-Analytical Finite Strip Method. Journal of Failure Analysis and Prevention, $1-10$.

[24]. Khani Aminjan, K., Kundu, B., \& Ganji, D. D. (2020). Study of pressure swirl atomizer with tangential input at design point and outside of design point. Physics of Fluids, 32(12), 127113.

[25]. Aminjan, K. K., Heidari, M., \& Rahmanivahid, P. (2021). Study of spiral path angle in pressure-swirl atomizer with spiral path. Archive of Applied Mechanics, 91(1), 33-46.

[26]. Tamm, A., Gugau, M., \& Stoffel, B. (2002, April). Experimental and $3 \mathrm{~d}$ numerical analysis of the flow field in turbomachines, part 1. In International Congress on Quality Assessment of Numerical Simulation in Engineering. 